Makrufa Sh. Hajirahimova ${ }^{1}$, Aybaniz S. Aliyeva ${ }^{2}$

${ }^{1,2}$ Institute of Information Technology of ANAS, Baku, Azerbaijan

$\underline{1 \text { makrufa@science.az }}, \underline{2 \text { aybeniz63@ } 6 \text { rambler.ru }}$

\title{
ANALYSIS OF INTERNATIONAL CHALLENGES AND EXPERIENCE OF FOREIGN COUNTRIES IN THE FIELD OF E-HEALTH
}

\begin{abstract}
Modern information technologies create new opportunities for helthcare. Their implementation in the healthcare is rapidly changing the diagnosis and treatment methods, the forms of doctors' interaction with patients and other doctors, the organization of treatment and restoration of health. Demands to more precise guideline principles of establishing the electronic health institutions and services has made it necessary to develop the national concepts and strategies in this field. This paper studies the e-health strategies and concepts of the international organizations and some developed countries. It also analyzes the current situation in the informatization of healthcare in Azerbaijan and proposes some recommendations in this regard.
\end{abstract}

Keywords: $e$-health, e-health records, health information systems, e-prescription, big data.

\section{Introduction}

The rapid development of information and communication technologies (ICTs) in recent years has resulted in the formation of e-health. E-health implies the use of electronic tools to provide information, resources, and services related to the health protection. This concept covers many areas such as electronic health records, mobile healthcare and health data analysis. E-health provides a wide range of personalized services and information access to people anytime and anywhere. The modern ICT enables the introduction of a variety of new methods of discovery, diagnostics and treatment of many diseases in medical practice. It also changes and improves the working techniques of health services $[1,2]$.

E-health has become a global phenomenon, creating unique opportunities for the development of public healthcare. At present, ICT applications in the field of healthcare are expanding and new services are created. Many countries have begun to implement the programs to establish a single information area in healthcare and social development spheres. According to the latest World Health Organization (WHO) estimates, more than $60 \%$ of countries prepare and implement their own eHealth strategies. The US, Canada and the European Union have been implementing the national programs on the informatization of healthcare for more than five years [1-4].

In 2012, the WHO and the International Telecommunication Union prepared a "Methodological guideline" on the national strategy in the field of e-health to assist the countries. The guideline presents the methodology for the preparation and implementation of the national concept, action plan and monitoring system of e-health, taking into account the national conditions and priorities of the countries $[4,5]$.

One of the key issues specified in the Concept of Development "Azerbaijan 2020: Look into the Future", adopted in Azerbaijan in 2012, is the fulfillment of tasks related to the health of the population and healthcare system. From this point of view, the informatization of healthcare can contribute to the development of health services, the health status of the population and the quality of medical services provided to the population [6]. Therefore, studying and benefiting from the best practices of advanced countries in e-health is crucial.

\section{E-health concepts of the international organizations}

Research shows that since the early 2000s, number of international organizations have started to focus on e-health. This topic was discussed at the World Summit on the Information Society of UN in December 2003 and at the $58^{\text {th }}$ session of the World Health Assembly in May 2005 and e-health resolution was adopted. Since then, the ICT has played a significant role in protecting health, providing healthcare and improving the health system in the world. WHO has 
launched a number of initiatives in the field of eHealth. For example, the WHO Global Health Observing Initiative aimed at "introducing the guidelines and strategic information on effective practices, policies and standards in the e-health to the Member States" was launched in 2005 [2].

In November 2005, the World Summit on Information Society in Tunisia, attended by 175 countries, discussed the some significant issues as the expansion of access to healthcare and telemedicine services, the integration of the network of specialists particularly for the improvement of health and well-being and the global co-operation in emergency situations [2].

In general, protection of the health of mothers and children in healthcare is one of the most important issues. In 2010, the UN Secretary General initiated the Global Strategy for the Protection of Women's and Children's Health. The Initiative aims to reduce the deaths of women and children. The strategy specifies supporting the national health policies, providing of the comprehensive services for prevention and treatment of women and children, taking measures to save lives, increasing the number of specialized staff to strengthen the healthcare systems, providing the innovative approaches to financing, financing the improvement of the monitoring and evaluation to ensure responsibility of all participating parties, and the significance of strengthening the policy and improving the services. Based on the WHO's Global E-Health Observing Initiative, 64 out of 75 countries with the highest maternal and child mortality have attended the development of the document. More than 300 e-health professionals in Mother and Child Health Protection have contributed to the development of this document [7].

E-health is a key component of the European Commission's E-Europe action plan. In 2006, the plans for defining the standards of joint use of health data for EU member states were identified. In 2008, the EU began to execute the plans for the introduction of health information networks and online services such as tele-consultation, e-recipe, e-mailing, tele-monitoring and remote diagnostics $[4,5]$.

In May 2011, the European Commission adopted E-Health Action Plan for 2012-2020. The main objectives of this plan are to expand the capabilities of the patients and healthcare providers, to coordinate the facilities and technologies, to invest in research in medicine, and to develop mobile healthcare [8].

This action plan is based on a number of innovative initiatives, such as epSOS (European Patients Smart Open Services). The main goal of this project, involving 23 European countries, is to achieve the trans-boundary links among the European electronic health record systems. This project, which was completed in 2013, has already given its contribution. Due to epSOS, the tourists, residents, or students will be able to securely access the high-quality health data beyond the country. E-health has enabled the nine leading regions to unite their efforts in the field of chronic diseases. Patients with diabetes and heart disease can care about their health recovery without leaving home $[8,9]$.

The Health-e-Child network, which is another example of the collaboration platform, provides the joint use of basic clinical information about heart and inflammatory diseases, and brain tumors in children by all European doctors and their early diagnosis [8].

The European Commission also finances the projects aimed at the study of deadly diseases. Or example, HAMAM project covers the early detection and precise diagnosis of breast cancer, euHeart - the diagnosis and treatment cardiovascular disease, and PASSPORT - the liver surgery [8]. There are many examples of ICT application in the health sector nowadays. Thus, the national programs on the informatization of healthcare are implemented in several European countries, the United States and Canada. The implementations in e-health field in Europe seem more attractive.

\section{e-Health policy of EU countries}

In the EU countries, a certain "e-health" program is being implemented $[2,10,11]$. The program aims at providing the processing of health information about the patient with the application of ICT, and providing the insurance regardless of the location of the patient. The 
program includes some projects on the use of electronic health records, personalization of health services, development of ICT infrastructure in the healthcare system, building the regional centers for health data, organization of electronic health data exchange, creation of single registries, reference books, and tele-health. The EU allocated 317 million euro to the implementation of the e-health program (excluding national EU programs) $[2,11]$.

To increase the efficiency and profitability of healthcare, the reliability and confidentiality of health data exchange is required to be ensured without the dissemination of personal information of the patients. Therefore, healthcare providers often use electronic health records [12].

In many cases, the relationships between the patients and the healthcare system begin from small health institutions. The advantages of using electronic health records arise in these circumstances. 59\% of the European Union member states have an electronic health insurance system, while $69 \%$ of these countries (31 countries) have adopted the legislative acts regulating the use of these records. These records are the key elements of the national e-health strategies. Electron health records provide access to complete and relevant information when providing first aid. However, the need for large expenditures for ICT and the lack of experience of healthcare professionals hinder the application of such systems [10,12]. At present, $66 \%$ of member states use to teach students the medical and sanitation behavior, and $71 \%$ use electronic trainings for preparing healthcare professionals. Holding electronic trainings within the framework of national health strategies can increase the knowledge and skills of healthcare professionals [10].

In many European countries, combined electronic health records are the central element of the e-health concept. The main purpose of merging the electronic health records and electronic disease records is to ensure the data safety and confidentiality, and to achieve the consent of the patient for data access. However, the complexity of modern security architecture and its integration with the health information technology systems requires a large amount of funds [9].

The availability of the legal framework is a key factor for the successful application of e-health. The legal framework for the protection of the privacy of electronic health data promotes the efficient use of e-health and enhances the patient's confidence in medical services. $80 \%$ of the member states have the national legislation in this field [10].

The scale of e-health in Europe is constantly expanding. The national services have been established on the basis of many programs in this area. $70 \%$ of European countries have developed the national e-health policies or strategies. The strategies in the field of e-health, including ethical principles, funding and education strategies, ensure its sustainable development. $62 \%$ of Member States have the national policies or strategies for tele-health, and $49 \%$ have state budget-funded mobile healthcare programs [10].

Analytical health data and Big Data have great potential in healthcare. Many health-related reports and newssheets show that Big Data can be used for the provision of public health, the identification and realization of the proper treatment methods for patients, the support of clinical development, and the management of the safety of healthcare system [13]. At present, only 13\% of European countries have national policies or strategies that govern the use of Big Data in the health sector, while the use of Big Data in $9 \%$ of countries is regulated by private companies [1, 10]. Recently, Big Data analytics has been widely used to better detect diseases and to conduct research in healthcare field. For example, the researchers dealing with the "human immunodeficiency virus" in the EU used IBM's Big Data tool set for the clinical genome analysis. Within the framework of EuResist project aimed at the treatment optimization, IBM's Big Data tool set has played a key role in understanding the clinical data of different countries by the researchers studying the "human immunodeficiency virus" during their treatment based on the empirical data [13].

A brief review of e-health practices of some European countries:

The Electronic Health Record Association, which incorporates basic German hospitals and clinics, local healthcare associations and regional healthcare networks, has developed a new improved concept of electronic health records technology [12]. This approach enables the health 
care professionals and system designers to focus on the business as it provides the safety and privacy of electronic health records. This approach allows users to access the regional healthcare network and also facilitates the involvement of new actors in healthcare [11, 14].

Due to the transition to e-health in Germany, the cost of existing healthcare is predicted to be reduced by up to $30 \%$. In particular, the use of e-prescription technology will save about 200 million Euro per year. It can also reduce the cost of treatment methods, additional procedures and misdiagnosis of medicines, saving about 500 million Euro annually. Moreover, detection and prevention of insurance frauds can save up to one billion Euro a year [11].

In 2002, the National Program for the Development of Information Technology was developed to improve the quality of all services, including the services for patients in the UK. A total of 11.4 billion pounds of funding was allocated to the implementation of the program. The main objectives of the program were to provide the national standards for the quality of data and their sharing, to provide the most appropriate systems for their application and to ensure the access of each patient to personal health records.

The UK National Health Service provides public health for all citizens (approximately 58 million people). In the UK, approximately $8.4 \%$ (189.84 billion pounds) of GDP is spent on health. However, in this country, the National Health Service still remains the main healthcare provider, with most of the population paying for health care at the expense of personal health insurance [13].

The British Parliament has issued a briefing on the necessity for the use of data (health and treatment records of the patients, status of the national healthcare system, diagnosis and treatment data), the digitization of health records, the management of public health and conducting scientific research [15].

The UK is currently implementing NHS Connecting for Health program. \$ 25 billion has been allocated to the implementation of this program. These programs are implemented in all countries of the Organization for Economic Co-operation and Development (OECD) [11].

In 2014, more than 30 million euro was allocated to the regional health information system, which was built in the administrative territory of South Denmark. The tendency of the Danish government to establish a single electronic infrastructure of existing administrative territories (since 2007) is also referred to the informatization of healthcare. Within the framework of the project implementation, it is planned to coordinate all health information systems. According to the program, each resident of the South Denmark region can get the necessary assistance from the regional health institution. At the same time, the hospitals will be capable to exchange information about the patients, regardless of their location. In addition, the Danish government has implemented a program that uses Big Data analytics to improve the quality and coverage of the care provided for the patients with chronic illness, including diabetes and heart disease $[11,15]$.

In Sweden, a national center has been set up for the informatization of healthcare. This center is practically making decisions for different regions of the country uniting the various regional organizations and government structures. Additionally, special organizations for project management, including e-prescription have been established within the national e-health strategy of Sweden. In general, about 2-3\% of the country's expenditure is spent on the use of information technologies. In the near future, this figure is predicted to increase to $7-8 \%[4,15]$.

The Swedish government has a high rate for the use of Big Data analytics. The reporting systems of the healthcare sector of the country are gathering the data streams from lab results, first aids and health centers. Additionally, the high quality of applied research enables large data collection to be jointly used by the industry actors in collaboration with the research institutes and academic circles. For example, the studies are carried out to ensure the efficient and effective decisions are made for medical and pharmaceutical research in the area of healthcare analytics. These studies include the development of methods and tools that support the study of the effects of drugs and the decision-making process through the data analysis [15]. 
The healthcare system of Estonia is one of the most advanced European systems. Since 2008, Estonia has started the introduction of an electronic health system. Estonia is the first state to adopt the national healthcare systems. In 2009, Estonia used a health data exchange mechanism to download all health records to the system. The use of e-health in this country is governed by the "Law on the Estonian Health Information System" and the "State Legislation on the Exchange of Health Information" [16]. Since 2010, the country has been using an e-prescription. More than 98\% of all prescriptions in Estonia are now electronic. Additionally, the hospitals have already started to issue the digital certificates on births and automated health insurance. Moreover, health records of 1.35 million people ( $98 \%$ of the population) have been included in the system. The electronic card system is an element of the largest e-Estonia system providing electronic government services such as electronic taxation, electronic school, single electronic state register of legal entities and electronic election system $[15,16]$.

The Health Data Center has been established in Estonia, which interacts with various mobile applications and practically collects information based on the ID card of each resident. The database covers the entire country and records all the data about the illness of the citizens "from birth to death". The data from the mobile devices like pulsmeter and pedometer is also possible to be voluntarily included into this database [11].

$I D$ card ensures secure access to all health data of the local patients through public portals eesti.ee or digilugu.ee. All e-health services provided to the citizens of Estonia are integrated into the e-service system. This system also incorporates 4 services, which are electronic health records, electronic registration office of clinics, X-ray images, and prescription services. Digital eprescriptions easily eliminate the need for paper recipes. This service is used in all pharmacies of Estonia [12].

\section{E-health policy of North American countries}

Since 2001, Canada Health Infoway company has launched a framework on the establishment of single health information system in Canada [17,18]. The implementation of the program has been allocated 1.3 billion USD. In 2006, Infoway worked out a comprehensive development strategy for e-health. The strategy aimed at providing the patients with quality and safe services, free access to health care, and more efficient use of health care resources. The strategy includes the establishment and expansion of an information technology infrastructure combining electronic health cards, clinics, hospitals, laboratories, pharmacies and other health institutions, the establishment of single registries, reference books and classifications, and the implementation of the projects in tele-medicine. About $\$ 400$ million Canadian dollars are allocated annually on the program execution $[17,18]$.

At present, the United States are realizing a comprehensive program the operation of a single health information system. This program chiefly includes the establishment of "Healthcare information system" segment within the e-government. The main coverage of the program includes electronic health records, national information infrastructure of healthcare, the informatization of the regional health information organizations and the health records of the population, the electronic exchange of health data [11, 19].

E-health in the United States has been implemented since February 2009 as a part of the legislative act on the "Use of health information technologies in economic activities and clinical practice", which provides the application and use of information technologies in healthcare $[11,19]$.

In March 2011, the US government launched a strategy for the introduction of ICT in healthcare. The main objective of the strategy is to improve the quality of the treatment of the patients and to encourage the physicians to use the health information systems [20,21].

The US National Center for Disease Control and Prevention and National Coordinator for Health Information Technology have adopted a number of standards. These standards govern the use of EHR, allowing health workforces and hospitals to get incentive rewards for certain criteria [19]. 
In 2015, the American electronic health card systems market totaled 9.3 billion USD [22]. The volume of investment in electronic health is forecasted to reach 21.6-43.2 billion USD in the following ten years. Despite the fact that health expenditures in the US are higher than other developed countries (15.3\% of GDP), health problems still remain here [19, 22].

The US government is particularly interested in the application of Big Data in the field of healthcare. In March 2012, the "Big Data Research and Development Initiative" proposed by the Obama Administration, the capabilities of large scale data are used in numerous areas, including biomedical research [23]. For example, 200 terabytes of data provided by the international 1000 Genomes Project on human genetics have been collected in cloud system of the US National Health Institute. The Amazon Web Services of the National Health Institute allow the researchers to access and explore these large volumes of data [24]. Within the framework of this initiative, the National Science Foundation and the National Institute of Health has started the implementation of Big Data project. The project mainly considers the development of the basic scientific and technological tools for management, analysis, visualization, and the extraction of useful information from various large volumes of data sets. The National Health Institute particularly focuses on the visualization of molecular, cellular, electrophysiological, chemical, epidemiological, clinical and other data related to health and disease. This can lead to the acceleration of scientific discoveries and new research areas [23, 25].

The Obama administration has proposed Health 2.0 project to effectively manage patients, health facilities and health insurance. The goal of the Pillbox model proposed by Health 2.0 is to provide precise information about the specific medicines that the users are interested in. The use of Big Data capabilities allows checking the sales of medical products and medical documentations, and facilitates supporting a clean health system. The use of Big Data analytics in Pillbox model has led to the reduction of annual health expenditure by 500 million USD [26].

\section{Informatization of healthcare in Asian and Pacific basin countries}

Since 2004, Australia has been providing health services and management based on the HealthConnect program, providing a safe, high quality and stable healthcare system for all citizens of the country. The main goals of HealthConnect are to provide accurate, flexible and reliable data availability and transmission among health care professionals, and to present customer-friendly information systems and to increase the access of the patients living in remote rural areas to electronic services for the improvement of health services and diagnostics [27].

In early 2008, Advisory Board of the Ministry of Health of Australia decided to establish an e-health national strategy for the development of electronic health. The goal of the strategy is to improve the quality of health services across all sectors of healthcare throughout the country [28].

Since 2012, Australia has been widely using personalized electronic health records. These records store information about the health of the patient, medication for treatment, their possible allergic features, pathogenic pathology and diagnostic results, including the results of blood or ultrasound examination [29].

In June 2013, an Australian e-health program "My child's e-health record" was launched. With this program, parents can access the child's health records and add any information (e.g. vaccinations, height, and weight) to it.

Australia has invested 8 million dollars in e-health development [25].

South Korea has the most advanced information technology infrastructure in the world. A flexible application of ICT in healthcare is being implemented here. The main targets of e-health in Korea are: providing lifelong health services on a personal electronic health card; improving the quality of health services; supporting medical research and improving health policies.

The introduction of personal electronic healthcare cards in this country provides high-quality health services anywhere and anytime. Although, some health problems still remain in the country. The main problem is that there are regional differences between the health services. Thus, most 
private healthcare facilities in the country are located in urban areas. $90 \%$ of doctors are concentrated in the cities. At the same time, $80 \%$ of the population lives in the cities. South Korea is becoming a faster aging society than any other country, including Japan. An increase in the number of elderly people has resulted in an increase in the expenses of healthcare. For example, the overall budget of e-health for 2005-2010 was 1.2 billion dollars. A health information system has been established in order to eliminate existing problems in the country and to develop e-health. Moreover, the following subsystems of these systems are used [13,30]:

- Enterprise Integration System - combines more than 3,500 health institutions providing standardized electronic health services.

- Remote Image Saving and Exchange System - provides specialized services for reading images for medical centers and hospitals without a doctor-radiologist.

- Drug use analysis system - checks the use of medicines in real-time mode and prevent their misuse. In this case, it performs the double check of drugs (in hospital and pharmacy).

- Drug Distribution System - provides a more transparent control of the whole chain of medicine supply.

- Korean insurance system - effectively controls the health services, claims, and financial resources through a combined control system.

An operational team has been established in South Korea for using Big Data and creating the necessary infrastructure. The main purpose of the team is to create a diagnostic system for commonly used data, Big Data network and analysis systems, which will facilitate the convergence of health data between the state and private sectors, guaranteeing security and confidentiality of personal data, developing Big Data technology infrastructure, including management and analytics technologies. The Korean Bio-Information Center is planning to create a "National DNA Management System". The system will provide diagnostics and treatment of the patients using large-scale data integration and health data of the patients [15].

Singapore, with its high-tech standards, aims to take a leading position for the use of new technologies and innovation capabilities in the field of healthcare. Singapore is ranked 6th in the world for health indicators, spending only 3-4\% of GDP in the overall health care system. Since 2011, the country has been switched to a national electronic health card system. This system is widely used in more than 280 healthcare facilities in the country. Each patient has an electronic health card. The availability and exchange of the patients' information among the health institutions ensures the provision of uninterrupted health service. The use of the hCloud (health cloud) reduces the cost of data sharing and the safety of health data in the healthcare sector [31].

Rapid aging of the population in Singapore creates many problems for the healthcare system. To meet the needs of aging demographics, in 2012, the government has adopted the Singapore Healthcare 2020 Masterplan. The strategy aims at improving the quality of health services provided to elderly people suffering from chronic illness through the use of digital healthcare tools [31]. Furthermore, the programs on tele-health, telemedicine, and mobile healthcare (mHealth) are also implemented in the country. The patients will be able to contact their physicians using the mobile devices and ask about their healthcare, medications, and laboratory analysis [31, 32]. The use of digital health technologies in Singapore, where more than 70 percent of their population is at above 50, is the next technological success of the country.

\section{E-health concepts of the CIS countries}

In April 2011, the Ministry of Health and Social Development of the Russian Federation adopted a resolution on the adoption of a concept for the establishment of a single state information system (SSISHC) in the field of healthcare [33]. In the first phase of SSISHC (2011-2013), thousands of treatment facilities were provided with the Internet access, automated job places were created, and the Health Information System was launched. In addition, basic federal services have 
been established such as registry surveys, electronic registration department, integrated electronic health card system, analysis systems of economic activity, the registration of health workforce and health centers. The next stage of the system building (2014-2020) includes the development of existing components, and the gradual involvement of more users in their use, and the expansion of automated functions. About 4.7 billion rubles have been spent on the development of the software for SSISHC.

The Republic of Kazakhstan has also adopted a development concept of electronic health for years 2013-2020. This concept has been developed taking into account the key priorities set out in the Strategy Kazakhstan-2050 and the State Program "Information Kazakhstan-2020". The concept of e-healthcare in Kazakhstan, which is planned to be implemented by 2020, primarily involves the creation of a safe, fair, quality and sustainable health system, which will enable the patients and the health care providers to access the information. Electronic health card is the key element of e-health in Kazakhstan. The card combines the following health information: 1) demographic data; 2) data about the conducted or existing diseases; 3) biometric data; 4) allergic and immune status [34].

\section{Concept of Informatization of Health sector in Azerbaijan}

Azerbaijan takes a leading position in terms of the development of ICT sector, the number of Internet and mobile users, and the sustainable economic development in the region. As in other areas, Azerbaijan has introduces the modern information technologies in the field of healthcare. Informatization of healthcare sector is basically realized by the decree of the President of the Republic of Azerbaijan on "Approval of the State Program for Development of Communication and Information Technologies in Azerbaijan for 2005-2008 (Electronic Azerbaijan)", the Decree of the Cabinet of Ministers and other legislations on the approval of the rules of application of "Electronic health card" and the determination of the rules for the establishment of the e-health registry. Moreover, the State Program for the Development of Communication and Information Technologies in the Republic of Azerbaijan for 2010-2012, and the National Strategy for the Development of the Information Society in the Republic of Azerbaijan in 2014-2020 and many government documents specify the development of e-health as a priority. In this regard, many implementations are planned, such as the establishment and development of the National Healthcare Network, which ensures all healthcare personnel and healthcare providers with secure broadband network connection; the development of an electronic health card system and provision of all age groups with electronic health cards; the expansion of the use of health information systems and the coordination with the e-health system; the creation of health resources for common use; the development of tele-health and the promotion of ICT skills of health workforce.

In general, the use of information technologies in the health sector in Azerbaijan, the monitoring of the population's health, the formation of the health information environment, the communication with other information systems and databases are the basis for the informatization of healthcare. In this regard, numerous projects are being implemented on electronic health card system of the citizens, exemplary health information systems, medical examination card system, dispatcher service of first aid, electronic database for monitoring of child immunization, electronic surveillance system and tele-medical systems for infectious diseases [10]. ] .In recent years, the electronic health card system has been introduced in Azerbaijan by the Ministry of Health, which includes personal, health and insurance data. The information contained on the card can be read and changed with special devices connected to computers in ambulances, hospitals, laboratories and drugstores. The information stored on the health card system (disease records, current medicines, vaccinations, health insurance, etc.) allows the card holder to be immediately and accurately examined.

The use of e-health in Azerbaijan and the elimination of the existing problems in this area require: 1) the creation of health information systems to ensure secure Internet access for 
healthcare personnel and health institutions; 3) broad introduction of the electronic health card system; 4) expansion of the application of health information systems and their coordination with the electronic health system; 5) holding electronic trainings to increase the knowledge and skills of healthcare providers; 6) creation of health resources for general use, the development of teleresource, the realization of tele-education, tele-medicine services, mobile health (mHealth) programs; 7) granting the financial support to e-health; 8) the use of cloud to ensure the safety of health data; 9) training the data scientists for conducting research in medical specialties [32].

\section{Conclusion}

The studies show that it is impossible to switch to a new model of health in the information society without the creation of e-health system. In this regard, the relevant UN bodies have called for the implementation of e-health systems and services in various countries. In response to these challenges, the health sector is being modernized at high speed. United States, UK, Estonia, Canada and other countries have been developing and implementing national programs, strategies and concepts in this field achieving positive results. These findings are related to health, financial, education, scientific research and economic fields, including medical and sanitary services. As indicated in the latest report of the World Health Organization, the development of e-health will primarily depend on the adoption and implementation of the legislation, financial support, improvement of medical education, and assessments. From this point of view, the establishment of a state policy and unique methodology in the field of e-health system development in Azerbaijan is one of the important issues.

\section{References}

1. Fact sheet - Status of eHealth in the WHO European Region, http://www.euro.who.int

2. Global Observatory for eHealth, http://www.euro.who.int/en

3. e-Health, http://www.openclinical.org/home.html

4. Luna D. R., Mayan J.C., García M.J., Almerares A.A., Househ M. Challenges and Potential Solutions for Big Data Implementations in Developing Countries //IMIA Yearbook of Medical Informatics, 2014, pp. 36-41.

5. National eHealth strategy toolkit. World Health Organization and International Telecommunication Union, 2012, http://www.itu. int/pub/D-STR-E_HEALTH.05-2012

6. Concept of Development "Azerbaijan 2020: Look into the Future", 2012, http://www.e-gov.az

7. eHealth and innovation in women's and children's health: A baseline review,2014, http://www.who.int/goe/publications/ehealth_ex_summary_en.pdf?ua

8. Innovative healthcare in the 21st century, 2015, http://www. ec.europa.eu

9. Cross-border health project epSOS: What has it achieved?, http://www.ec.europa.eu

10. From innovation to implementation - eHealth in the WHO European Region, 2016, http://www.euro.who.int/en/publications/abstracts/ 2016

11. International experience in the informatization of healthcare, http://www.filearchive.cnews.ru/img/reviews/2014

12. Electronic health records become reality, http://www.citforum.ru/computer/2012-11

13. 10-Jee K., Gang-Hoon K. Potentiality of Big Data in the Medical Sector: Focus on How to Reshape the Healthcare System // Healthcare Informatics Research, 2013, vol. 19, no. 2, pp. 79-85.

14. Schulte O. Development of the healthcare system: German experience in healthcare, 2012, http://www.gosbook.ru/node/63986.

15. The Use of Big Data in Public Health Policy and Research: Background information document, 2014, 19 p., http://www.ec.europa.eu/health 
16. E-health in practice, http://www.euro.who.int/en/data-and-evidence/news/news/2016/01/ehealth-in-practice

17. Electronic Health Records in Canada: An Overview of Federal and Provincial Audit Reports, 2010, 22 p., http://www.gov.pe.ca/photos/original/ag_ehealth.pdf

18. Annual Report of the Canada Pension Plan 2011-2012, http://www.esdc.gc.ca/en/reports/pension/cpp_reports/2012/cpp_report.page

19. Vestc J.R, Gamm L.D, Health information exchange: persistent challenges and new strategies //Journal of the American Medical Informatics Association, 2010, vol. 17, no. 3, pp. 288-294.

20. http://www.healthit.hhs.gov/portal

21. http://www.apps.who.int/iris/bitstream/10665/75211/, 2011.

22. Analytics. Electronic health record, 2016, http://www/osp.ru.

23. Big data is a big deal, 2012, http://www.whitehouse.gov/blog/

24. http://www.nsf.gov/news/news_summ.jsp?cntn_id=12360710

25. 1000 Genomes Project data available on Amazon Cloud, http://www.nih.gov/newsevents/news-releases/

26. E-health - when, not if , 2016, http://www.euro.who.int/en/home

27. Health Connect, 2011, http://www.health.gov.au/healthconnect

28. National E-Health Strategy, 2012, http://www.health.gov.au/internet/main/publishing.nsf/

29. Australia develops e-healthcare, 2013, http://www.open.gov.ru/events/5511607

30. Hon P. The development of national e-health in the example of South Korea, 2012, http://www.gosbook.ru/node/63986.

31. EnriquezJ. The Role of Digital Health in Singapore's Healthcare Landscape, 2014, https://innovatemedtec.com/content/the-role-of-digital-health-in-singapores-healthcarelandscape

32. Hajirahimova M. Sh.The big data era in healthcare: promises and challenges // Problems of information technology, 2017, №1, pp. 64-72.

33. Informatization of health care, http://www.studopedia.org/

34. The state program "Information Kazakhstan -2020" http://www.egov.kz/wps/portal 